\title{
Entramados de historia social del trabajo en perspectiva de género: recorridos y desafíos historiográficos. Argentina, siglo XIX y XX
}

\author{
Florencia Gutiérrez \\ Instituto Superior de Estudios Sociales. \\ Universidad de Tucumán. CONICET, Argentina \\ Valeria Silvina Pita \\ Instituto Interdisciplinario de Estudios de Género. \\ Universidad de Buenos Aires. CONICET, Argentina
}

En las últimas décadas, la historia social del trabajo en perspectiva de género impulsó investigaciones acerca de un conjunto de problemas que fueron complejizando la agenda historiográfica con foco en los siglos XIX y XX en Argentina. Las formas en que comenzaron a ser leídas determinadas experiencias de varones y mujeres --quienes de distintas formas buscaron su subsistencia, se asociaron, lucharon y demandaron por sus intereses y derechos -- se convirtió en un campo que revisó problemas, articuló preguntas y arrojó nuevas interpretaciones históricas. Este dossier se organiza en torno a un norte o sentido de unidad, que propone reflexiones situadas sobre algunas de las maneras en que fueron construidos y revisitados determinados problemas históricos que cruzan al trabajo, al género, a la clase y la raza. Para avanzar en esa reflexión las autoras aceptaron un desafío metodológico: partir de una evidencia concreta que, a modo guía, les facilitara enlazar algunas de las dimensiones historiográficas de sus ensayos. En cada uno de los cinco artículos que componen este dossier, el corpus documental se convierte en un disparador que contribuye, de forma sensible y empírica, a identificar preguntas, problemas y decursos de pesquisa. A la par, estos escritos invitan a ponderar algunas de las posibilidades de revisitar una fuente histórica a la luz de diversos interrogantes. Cada ejercicio permitió distinguir cómo determinados cuestionamientos recuperan, dialogan o se diferencian de otros que fueron identificados y expuestos en disímiles momentos históricos y, por ende, en distintivas coyunturas historiográficas.

Partir de unas evidencias para divisar algunas de las distinciones con las que fueron interpeladas a lo largo del tiempo, constituye una invitación hacia lxs lectorxs: la de unir la reflexión historiográfica a las marcas que hacen directamente al oficio de la historia en su dimensión de trabajo empírico.

El dossier comienza con el escrito de Gabriela Mitideri y Valeria Pita que recupera un cuaderno manuscrito de tapas verdes confeccionado en el Asilo de Mendigos, del municipio de Buenos Aires, para albergar a hombres y mujeres pobres, enfermas, y sin redes familiares. Volver a esta fuente con nuevas preguntas les permite a las autoras poner en tensión unas divisiones establecidas en la historia del trabajo: los pares dicotómicos que escindieron el trabajo de la pobreza, el trabajo libre del trabajo esclavo y el trabajo productivo del trabajo de servir realizado en residencias o estancias de habitación. En décadas pasadas, los registros oficiales de las instituciones de caridad pública fueron interpelados para pensar la pobreza, disociando su presencia de los mundos del trabajo y de las experiencias sociales de trabajadoras y trabajadores. Este ensayo intenta deshacer esa división, indagando a ese registro documental por las trayectorias laborales de zapateros, cocineras, esclavas, artesanos, costureras, entre otros y otras que por diversas causas anclaron en un momento en ese asilo. Bajo el amplio paraguas del Fondo Documental de la Sociedad de Beneficencia de la Capital Federal, sito en el Archivo General de la Nación, se ubican los textos de Cecilia Allemandi e Inés Pérez. La primera autora trae a la luz unos contratos de trabajo elaborados bajo el auspicio de la agencia de 
origen rivadaviano, compuesta íntegramente por mujeres, para dar colocación a mujeres y varones indígenas capturados en las denominadas "guerras contra el indio" a mediados de la década de 1880 en la ciudad de Buenos Aires. Observar con detenimiento a esta documentación escrita, concede un lugar de privilegio para reflexionar sobre las prácticas de entrega y colocación de indígenas en la sociedad porteña y preguntar cómo esas experiencias de trabajo no remunerado contribuyeron a la etnización de esas poblaciones y a profundizar una integración subordinada. Asimismo, atributos como la llamada condición étnica, el género y la edad son puestos en locución para repensar cómo fueron empleados por autoridades públicas y benefactores para justificar políticamente el destino de esas mujeres, niñas y niños que fueron colocados como sirvientes y criados. Por su parte, Inés Pérez, revisita un conjunto de legajos de niños y niñas abiertos por la Sociedad de Beneficencia a mediados del siglo XX para abordar las experiencias de la maternidad de mujeres trabajadoras, especialmente de quienes se desempeñaban en el servicio doméstico. Aunque este tipo de registros sirvió en otras agendas historiográficas para pensar a las propias instituciones asilares, las políticas de disciplinamiento o las de control social, en este caso, los interrogantes de Pérez permiten repensar la agencia histórica de las trabajadoras, la forma en que sus empleos constreñían sus vidas más allá de lo laboral y --a la par-- para informar sobre sus márgenes de acción, sus capacidades para desarrollar estrategias de cuidado hacia sus hijos y negociar unos criterios, a partir de los cuales las agencias estatales las evaluaban como madres. Así, unas maternidades son devueltas a los mundos del trabajo de mitad del siglo XX.

Una denuncia policial realizada en la localidad bonaerense de Las Flores en 1909 por una mujer, quien acusó a un trabajador ferroviario de haber abusado de ella y de sus hijas de dieciocho y quince años de edad, es el disparador del que se vale Florencia $\mathrm{D}^{\prime}$ Uva para reponer a las emociones y los afectos como una dimensión constitutiva de la experiencia obrera de comienzos del siglo XX. Esta fuente le permite desandar unas vivencias familiares y dinámicas afectivas que se distancian del imaginario del "hogar ferroviario" como un espacio sustentado en la figura responsable del jefe de familia. Este movimiento por los márgenes se convierte en un observatorio privilegiado para tensar e historizar unas convenciones, normas y valores esperables en los sujetos involucrados en la denuncia; reponer unos subjetivos y fluctuantes límites domésticos entre lo tolerado y lo desmedido. Pero también, este ensayo nos devuelve las estrategias de negociación, resistencia activa y sobrevivencia esgrimidas por Angélica Solores, quien un día se presentó ante el comisario de la localidad para denunciar a su pareja, Bonifacio Estrella.

Graciela Queirolo recupera los censos nacionales de 1914, 1947 y 1960 para repensar el trabajo femenino asalariado y complejizar los límites y posibilidades de una fuente que, a la luz de las interpelaciones propuestas por la autora, todavía tiene mucho por decirnos. En su texto, enfatiza la construcción social de sentido inherente a las cifras, propuesta que impulsa una lectura alternativa de los materiales censales al reponer la dosis de incertidumbre y ansiedad que signó a los intérpretes de la creciente y diversificada participación de las mujeres en el mercado de trabajo. Este ejercicio le permite analizar cómo los registros censales --sustentados en la fuerza de un imaginario articulado en torno de un trabajador universal masculino-- coadyuvaron a ignorar la experiencia femenina asalariada y reproducir implícitamente la división sexual del trabajo, operación que alentó un imaginario en términos de "estancamiento" de la participación económica femenina y una valoración que subrayó el carácter excepcional y complementario del trabajo de las mujeres.

En suma, el esfuerzo de las colaboraciones aquí reunidas vuelve explícita la historicidad del conocimiento histórico y transparenta su plural, crítica y problemática construcción. Apostar por este tipo de ejercicio permite reconocer unas características situadas de la historia social del trabajo en nuestro país. Estos cinco artículos traen a primera plana algunas de las formas en que se articularon y releyeron las llamadas fuentes, en función del movimiento del tiempo y, a la par, nos devuelven preguntas y metodologías de investigación que se distinguen de otras regiones y academias nacionales. La factura de este dossier alienta una mirada caleidoscópica que permite también divisar cómo se tensaron, disputaron y renovaron unos consensos al interior de la historiografía social del trabajo. Resulta alentador seguir preguntándonos por cómo hacemos historia social del trabajo en perspectiva de género, repensando cómo las distintas coyunturas inciden en las 
interpelaciones, priorizan unos cuerpos documentales, usan unos vocabularios y unas categorías históricas e historizables y reponen unas preguntas sobre otras. A futuro, y en razón de las múltiples dimensiones de ese proceso vital e indeterminado de hacer historia, esperamos que este desafío siga siendo recuperado. Sin duda, nuevas reflexiones historiográficas colaborarán en distinguir insospechadas posibilidades de interpretación empírica sobre el pasado de lxs trabajadorxs. 